\title{
Variations
}

Variations

Revue internationale de théorie critique

$13 / 14 \mid 2010$

Le choix du petit

\section{Mondes du travail et espace public. Le faire et l'agir?}

Alexander Neumann

\section{(2) OpenEdition}

Journals

\section{Édition électronique}

URL : http://journals.openedition.org/variations/181

DOI : 10.4000/variations. 181

ISSN : 1968-3960

Éditeur

Les amis de Variations

Édition imprimée

Date de publication : 31 mars 2010

\section{Référence électronique}

Alexander Neumann, « Mondes du travail et espace public. Le faire et l'agir ? ", Variations [En ligne], 13/14 | 2010, mis en ligne le 01 février 2012, consulté le 19 avril 2019. URL : http:// journals.openedition.org/variations/181; DOI : 10.4000/variations.181

Ce document a été généré automatiquement le 19 avril 2019.

Les ami•e•s de Variations 


\title{
Mondes du travail et espace public. Le faire et l'agir?
}

\author{
Alexander Neumann
}

\section{NOTE DE L'ÉDITEUR}

Première publication sur www.theoriecritique.com, « Le choix du petit », Printemps 2010, pp. 91-95

\section{NOTE DE L'AUTEUR}

Thèses mises en débat au colloque international Journées critiques, Université Lumière Lyon, mars 2010, organisé par Dietrich Hoss. Voir http://journeescritiques.canalblog.com

\section{Face au parti ouvrier}

1 L'identification réductrice du prolétariat avec la classe ouvrière organisée, masculine et syndiquée, puis avec « le parti de la classe ouvrière » a dominé la scène publique entre la fin du 19e siècle et la chute du mur, avec des paliers d'érosion après 1968, 1978, 1989 et 1999. La traduction politique du monde du travail vers l'espace public bourgeois, parlementaire et discursif, a été monopolisée par le parti ouvrier, les partis ouvriers. Exemples de l'apogée et du déclin de cette figure : Le PCF, le SPD. Leurs relances restent isolées.

\section{Le tournant linguistique}

2 Cet arrière-fond historique a justifié une théorisation qui a connu son plein essor dans les années 1980, et qui a organisé la coupure entre le monde du travail et la politique, le 
salariat et la prise de parole, l'existence matérielle et la morale, le faire et l'agir. $L a$ Distinction de Pierre Bourdieu (les ouvriers ne peuvent pas prendre la parole), la Sociologie d'Alain Touraine (le travail ne peut plus entrer en action), la Théorie de l'agir communicationnel de Jürgen Habermas (le prolétariat est une masse apolitique) sont les milestones de cette conception. Chez Habermas, le marché et l'Etat (l'argent et le pouvoir) assurent une socialisation de masse qui dégage l'espace d'une délibération éclairée.

\section{L'héritage francfortois}

3 Habermas et Honneth ont enterré cet héritage critique de l'Ecole de Francfort, qui lie la critique de l'économie politique aux formes sociales fétichistes et à la mise en question des fonctions autoritaires de l'Etat. L'industrie de la culture désigne les effets du fétichisme de la marchandise sur l'espace public bourgeois. Les études sur la personnalité autoritaire saisissent les entraves à l'action autonome, la recherche sociale sur le travail salarié depuis l'après-guerre unit la compréhension du travail salarié et la critique du travail. Wilhelm Reich, Erich Fromm, Herbert Marcuse, Oskar Negt et Alexander Kluge, Gerhard Brandt, Jean-Marie Vincent, Nancy Fraser, John Holloway et alli, sont des auteurs que les discours habermassiens critiquent au nom de l'Institution, contre un héritage critique. Habermas a rejeté cet héritage: "Habermas hat dieses Erbe ausgeschlagen » (Detlev Claussen in Arbeit und Utopie, Online Verlag, 2004).

\section{Crises}

En 2009, l'écho de la grande crise de 1929 est devenu audible. Crise mondiale du capitalisme, banqueroutes bancaires, précarité et chômage de masse, crises politiques dans plusieurs pays européens (Islande, Grèce), instabilité d'autres (Portugal, France, Espagne, Italie). Grèves générales, expressions politiques imprévues, apparition de nouveaux espaces publics oppositionnels à partir des Universités, des villes, des mouvements sociaux, contredisent la conception habermassienne. Les Parlements interviennent massivement dans le marché, l'opinion publique est polarisée par la précarité du travail, etc. Le marxisme doctrinaire, le libéralisme, la théorie de l'agir communicationnel sont dépassés par les événements.

\section{Espace public bourgeois, espace public oppositionnel}

Honneth: «Le CPE bat en brèche les attentes de reconnaissance du travailleur » (Le Monde, 3.4.06). Le salariat et l'espace public interagissent, le travail et la morale échangent, mais sa théorie ne suit pas. Ce que l'espace public bourgeois ne contient plus puisque les partis, le Parlement et la presse ont soutenu le leitmotiv du CPE - l'espace public oppositionnel le verbalise : l'expérience vécue des effets du salariat. Précarité, stages, influence des attentes marchandes sur l'enseignement, menaces de licenciement, contraintes du salariat, critique du travail.

L'espace public oppositionnel est le lieu où l'expérience singulière puisse se faire entendre, le lieu de la prise de parole qui n'a pas sa place dans les mass media fétichistes, 
l'espace politique représentatif et les institutions républicaines. Ici, la critique de l'économie politique se nomme.

\section{L'oikos danse à l'agora}

6 Habermas voulait avoir raison avec Arendt, contre Marx. Ici, l'oikos serait un lieu apolitique et servile, contre la politique et la délibération à l'agora. Pourtant, la lecture grecque d'Arendt appelle d'autres considérations à l'heure de la crise grecque. Au siècle de Périclès, l'oikos était le lieu de la vie sociale de la cité grecque, ou se passait la communication sociale et l'inspiration spirituelle, alors que L'agora était interdite aux femmes, aux métèques et aux étrangers. Arendt tournait la philosophie grecque contre le marxisme soviétique, avec Marx. Habermas la tourne contre la critique de l'économie politique. Honneth tourne en rond.

\section{L'expérience et le concept}

7 Le faire ne se fait jamais sans conception, intuitive, formelle ou consciente. L'agir ne se passe pas du travail, comme Adorno l'a soutenu contre Hegel. Aussi, l'expérience est interprétée à la lumière des concepts disponibles, tandis que la formulation des concepts dépend de l'expérience. Chez les philosophes grecs et chez Emmanuel Kant, «ce penseur allemand de la Révolution française ", dixit Karl Marx. Penser le faire sans l'agir est une illusion spéculative, selon les Trois études sur Hegel (Adorno). C'est pourquoi l'agir communicationnel n'existe pas en dehors du travail, dans une société basée sur l'échange marchand.

\section{Une subjectivité superflue}

8 L'Etat et le marché mobilisent une subjectivité des acteurs qu'ils ne peuvent résorber. L'Etat appelle à la mobilisation des citoyens pour la heurter sous des formes bureaucratiques, le marché et l'entreprise mobilisent le travail selon le principe de l'éthique protestante sans se soucier des motivations existentielles des salariés. La subjectivité superflue se manifeste partout, surtout en période de crise. Elle engage des quêtes de sens et une critique qui ne se réduit nullement aux principes organisateurs de la société bourgeoise. Elle poursuit une dialectique négative que le management politique ou économique ignore.

\section{Le choix du petit}

9 La droite et la gauche parlementaire, les mass media, les philosophes français nous écrasent avec le principe de l'intérêt général, ce compromis injuste, précaire et asymétrique que l'Etat négocie pour modérer les rapports de domination qu'il organise. Chez Adorno, cette vision est perçue comme une doctrine, où le "général écrase le particulier » (Minima Moralia), où l'Histoire lamine l'expérience vivante et singulière, où le pas de l'oie tente de faire la dissonance, où l'identité nationale massacre la différence. La morale la plus élémentaire nous conseille de résister à ce principe. 


\section{AUTEUR}

\section{ALEXANDER NEUMANN}

Sociologue, Institut für Sozialforschung, Saarbrücken. 